\title{
Preparation of Activated Carbon from Holdfasts of Kelp, Large Brown Seaweed, Saccharina japonica
}

\author{
Osamu Terakado*, Futoshi Tanaka, Yuki Tsunamori \\ Department of Material and Environmental Engineering, National Institute of Technology, Hakodate College, Hakodate, Japan \\ Email: *terakado@hakodate-ct.ac.jp
}

How to cite this paper: Terakado, O., Tanaka, F. and Tsunamori, Y. (2021) Preparation of Activated Carbon from Holdfasts of Kelp, Large Brown Seaweed, Saccharina japonica. Engineering, 13, 71-81. https://doi.org/10.4236/eng.2021.132006

Received: January 29, 2021

Accepted: February 22, 2021

Published: February 25, 2021

Copyright $\odot 2021$ by author(s) and Scientific Research Publishing Inc. This work is licensed under the Creative Commons Attribution International License (CC BY 4.0).

http://creativecommons.org/licenses/by/4.0/

\section{(c) (i) Open Access}

\begin{abstract}
Dried kelp is one of the most important Japanese foods mainly used as base ingredient. Holdfasts, or rhizoids, of kelp are usually discarded, as rocks, shells, ropes and other contaminants are entangled among them. The purpose of the present study was to examine whether the preparation of activated carbon from holdfasts of Saccharina japonica, a popular kelp harvested in Japan, is possible by a chemical activation technique utilizing zinc chloride, and to study the influence of the process parameters, such as carbonization temperature and the composition of the activator. Under the examined experimental conditions, maximum specific surface area of $1.7 \times 10^{3} \mathrm{~m}^{2} / \mathrm{g}$, larger than that of a commercial activated carbon, was observed at $600^{\circ} \mathrm{C}$ and the zinc chloride composition of 75 mass\%.
\end{abstract}

\section{Keywords}

Holdfast, Kelp, Activated Carbon, Zinc Chloride

\section{Introduction}

Kelps are large brown algae seaweeds, commonly used as base ingredients in Japanese food. In 2018 ca. 56,000 tons were harvested in Japan, around 95 percent of which were from Hokkaido Island [1]. As large amounts of kelps are used in food industries, they are even aquacultured widely along the coast of the island. Small kelps are inserted into ropes, and then aquacultured over the period of one or two years, growing up to the length of $10 \mathrm{~m}$. Holdfast, or rhizoid, of kelp is the stem part of the kelp body to anchor the kelp body to the substrates, ropes in the case of aquaculture, being cut after harvesting. It is also edible, although usually discarded as rock particles, shells, ropes and other conta- 
minants are easily entangled among the holdfasts because of their complex twining structure. A considerable amount of holdfast waste is discharged every year, reaching 2000 tons for aquacultured kelps in southern region of the Hokkaido Island [2]. Therefore, it is important to develop an effective utilization of the kelp wastes.

Kelps contain many polysaccharides, such as alginate and fucoidan, within the kelp cells. As these polysaccharides have functional groups which exhibit the cation-exchange properties, they can be used for the hydrometallurgical recovery of various metal ions [3] [4]. We have previously shown that Saccharina japonica, SJ, formerly called Laminaria japonica, and Saccharina sculpera, both popular kelps in Japanese foods, could be successfully applied for the recovery of divalent metal ions [5].

Other kinds of the utilizations of kelp holdfasts have been also considered for the kelp wastes. The composting is one of the options [2], although it does not gain popularity because of the costly process involving the separation of the above-mentioned various contaminants. Particularly, the contamination of nylon ropes is regarded as crucial in the process. The production of biodiesel is also an attractive alternative method for the energy recovery from aquatic biomass. $\mathrm{Xu}$ et al. succeeded the microbial oil production from SJ [6]. The influence of the contamination should be further examined for the application of the kelp holdfasts.

Among the other processes, the carbonization of organic waste is one of the most promising methods. The carbonization of seaweeds has been studied in a variety of literature [7]-[14]. The hydrothermal technique has been mainly considered in the view of avoiding the energy-consumptive drying process [7] [8]. On the other hand, harvested Japanese kelps are usually dried for the food industry, so that the carbonization of the dry matter of kelps is worth to be investigated. We have, therefore, studied the preparation of activated carbon from dried holdfasts of SJ in the present work. The chemical activation method utilizing zinc chloride activator [14] [15] was employed, and the influence of the various process parameters, such as carbonization temperature and the composition of $\mathrm{ZnCl}_{2}$ have been examined.

\section{Materials and Methods}

\subsection{Materials and Sample Preparation}

The process flow for the preparation of activated carbon is shown in Figure 1. Holdfasts of Saccharina japonica were kindly supplied from local fisheries in Hakodate region, southern Hokkaido, Japan. In the present work impurities of ropes, shells and so forth adhered to the holdfasts were thoroughly removed prior to the experiment in order to exclude their influences. Then the holdfasts were washed by water and air-dried. The dried holdfasts were then shredded with a cutter mill. After sieving, the fraction under $350 \mu \mathrm{m}$ was used for the following process. The holdfast powder was mixed with the reagent grade zinc 
chloride powder (Wako pure chem. Co., Ltd.) as activator and the mixture was heated at $600^{\circ} \mathrm{C}$ or $900^{\circ} \mathrm{C}$ under argon atmosphere. The apparatus for carbonization and activation is schematically shown in Figure 2, which is principally the same as that employed for the preparation of activated carbon from polyester resins [16] [17]. A quartz horizontal reactor (inner diameter of $26 \mathrm{~mm}$ and the length of $1000 \mathrm{~mm}$ ) was heated in an electric furnace. Approximately $2 \mathrm{~g}$ of the sample mixture were placed on a ceramic boat, then it was placed into the center of the reactor. The incoming Ar gas was adjusted at a flow rate of $100 \mathrm{~mL} / \mathrm{min}$. The samples were heated at the rate of $10^{\circ} \mathrm{C}-15^{\circ} \mathrm{C} / \mathrm{min}$, and kept for 1 hour at constant temperature. Carbonization products contain zinc components originating from zinc chloride, which may adversely affect the properties of activated carbon. They were, therefore, cleaned with $\mathrm{HCl}$ aqueous solution (ca.1 mol/L) to remove the zinc components.

\subsection{Characterization Methods}

The pyrolysis characteristics of holdfasts were analyzed by Thermogravimetry/Differential Thermal Analyzer (TG-DTA) (Rigaku, Thermoplus TG8120). Dried holdfast powder with a particle size of under $350 \mu \mathrm{m}$ was used as a sample. Temperature was rose from room temperature to $1000^{\circ} \mathrm{C}$ at a heating rate of $10^{\circ} \mathrm{C} / \mathrm{min}$. Helium was used as a carrier gas at a flow rate of $100 \mathrm{~mL} / \mathrm{min}$. Aluminum oxide, $\mathrm{Al}_{2} \mathrm{O}_{3}$, was chosen as a reference material for DTA measurements.

Specific surface area of samples was measured at $77 \mathrm{~K}$ by a specific surface meter (Shimadzu, FLOWSORB 2300) based on the Brunauer, Emmett and Teller, BET theory using the flowing gas $\left(30 \% \mathrm{~N}_{2}-70 \% \mathrm{He}\right)$ method. Commercial activated carbon (Wako pure chem. Co., Ltd.) was used for comparison. A scanning electron microscope, SEM, (JEOL, JSM-6360LA) was used to observe the surface morphology of carbonized and activated samples.

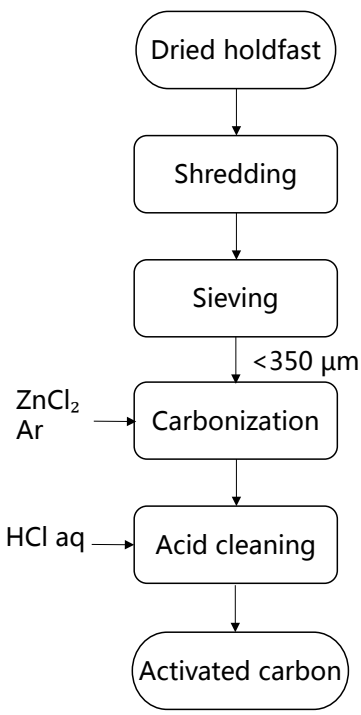

Figure 1. Schematic representation of the activated carbon preparing process. 


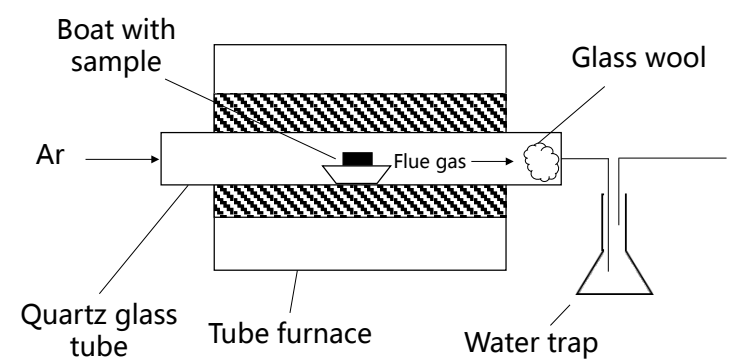

Figure 2. Apparatus for carbonization/activation experiments.

Elemental analysis of carbon, hydrogen, and nitrogen in samples was conducted with Yanaco MT-6 equipment to determine the carbon yield, elemental composition, and the ash content. The X-ray diffraction (XRD) technique was used to investigate whether the obtained activated carbon after hydrochloric acid washing contained an inorganic crystal component or not. In addition, the efficiency of acid cleaning at different heat treatment temperatures and at different $\mathrm{ZnCl}_{2}$ proportions were compared.

Gas chromatography/mass spectrometry, GC-MS, (Agilent, GC6890 and JEOL JMS-Q100GC MKII) was used to evaluate the chemical species contained in the off gas during thermal treatment. A flask containing $250 \mathrm{ml}$ of acetone was set instead of the water trap in Figure 2 to capture the volatile pyrolytic products. InertCap 1 column was used for the GC-MS analysis.

\section{Results and Discussion}

\subsection{TG-DTA}

The results of TG-DTA analysis of holdfasts are shown in Figure 3. The solid line represents the result of TG, and the dotted line is that of DTA. From the TG result, it can be seen that continuous weight-loss occurred after the evaporation of water contained in the sample around $100^{\circ} \mathrm{C}$, suggesting that the decomposition of various organic substances contained in holdfasts of the kelp sample, such as cellulose, fucoidan, and alginic acid take place over the wide temperature range. This is also confirmed by the complex endothermic DTA peaks. As for the carbonaceous compounds remaining as residue, approximately $70 \%$ of weight was lost at $600^{\circ} \mathrm{C}$. The continuous weight reduction stops apparently above $900^{\circ} \mathrm{C}$. On the basis of the result of TG, carbonization temperature at $600^{\circ} \mathrm{C}$ and $900^{\circ} \mathrm{C}$ was examined in the present study.

\subsection{Carbonaceous Product Yields}

The yields of carbonaceous compounds were calculated by the ratio of the weight of the sample after washing with hydrochloric acid to that of the initial holdfast sample before heating. The results are summarized in Figure 4. The yield of kelp without zinc chloride was $\sim 43 \%$ at $600^{\circ} \mathrm{C}$, comparable to the result of TG experiment. Comparing the results of samples heated at $600^{\circ} \mathrm{C}$ and $900^{\circ} \mathrm{C}$, the yields at the higher temperature of $900^{\circ} \mathrm{C}$ are low, which can be ascribed to the decomposition and the consequent evaporation of the organic substances at 
elevated temperature as mentioned in the previous section. The yield decreased by $10 \%$ to $20 \%$ by the chemical activation, and the weight-loss ratio increased with increasing the $\mathrm{ZnCl}_{2}$ content. This is considered as the result of the weight reduction caused by the dehydration reaction in the presence of $\mathrm{ZnCl}_{2}$, a well-known Lewis acid [18] [19].

\subsection{Specific Surface Area}

Figure 5 shows the changes in the specific surface area of the samples as a function of zinc chloride composition. The carbonized samples without the activator have very small specific surface areas of 9.1 and $11 \mathrm{~m}^{2} / \mathrm{g}$ at $600^{\circ} \mathrm{C}$ and $900^{\circ} \mathrm{C}$, respectively. It is clear that the addition of zinc chloride increased significantly the specific surface area, showing the high activation effect. When the proportion of zinc chloride increased, the value of the specific surface area also increased. At the heating temperature of $900^{\circ} \mathrm{C}$ and the zinc chloride composition of $75 \%$, the specific surface area is comparable to that of a commercially available activated carbon.

At the same composition of zinc chloride, larger specific surface area was observed at the activation temperature of $600^{\circ} \mathrm{C}$ than of $900^{\circ} \mathrm{C}$. It is known that the micropores are developed by the expansion of molten $\mathrm{ZnCl}_{2}$ above its melting point of $300^{\circ} \mathrm{C}$, resulting in the formation of mesopores, while further increase in temperature gives rise to the shrinkage of the carbonaceous pores [20]. The present results indicate that the latter is the dominant process above $600^{\circ} \mathrm{C}$ for the carbonization of kelp holdfast in the presence of $\mathrm{ZnCl}_{2}$.

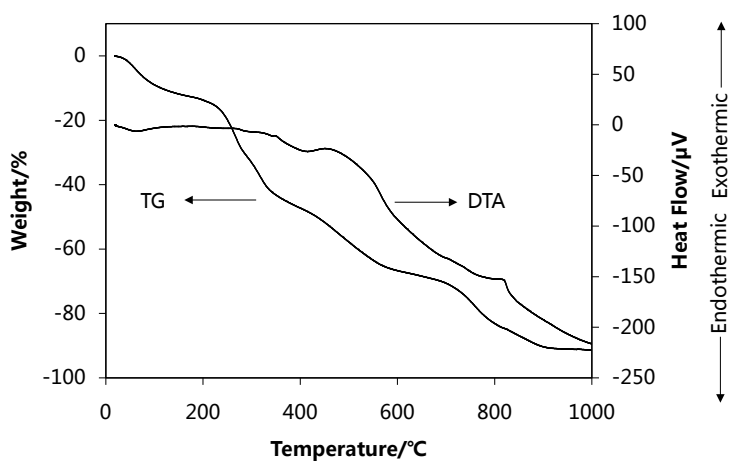

Figure 3. TG-DTA curves of holdfasts of kelp sample.

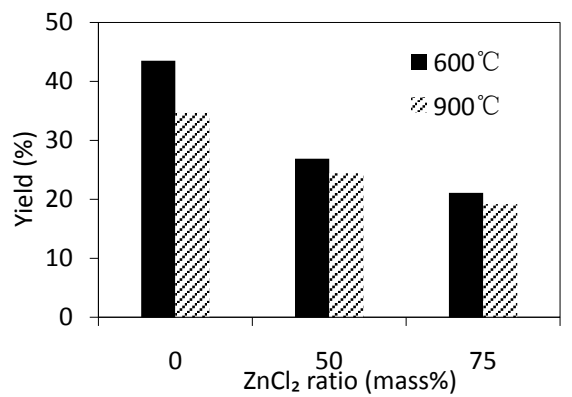

Figure 4. Yield of carbonization/activation products at three $\mathrm{ZnCl}_{2}$ compositions. Filled bars are the results without $\mathrm{ZnCl}_{2}$ and the shadow bars with the activator. 


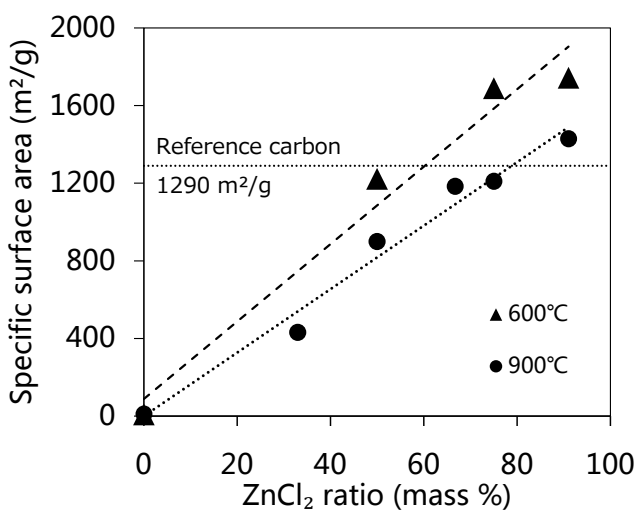

Figure 5. Specific surface area as a function of zinc chloride composition.

\subsection{Surface Morphology}

The surface morphologies of carbonized and activated samples observed with SEM are shown in Figure 6. The rough particles found in the sample surface are considered to be zinc compounds and/or ash impurities originally existing in the kelp samples. Comparing the carbonized sample without $\mathrm{ZnCl}_{2}$ (a) and activated product $(b, c)$, the activated sample had a smoother surface. Therefore, it can be seen that impurities are reduced by activation and acid cleaning. As for the influence of temperature, the samples treated at $900^{\circ} \mathrm{C}$ showed pores with a diameter of about $5 \mu \mathrm{m}$. The formation of macro-sized pores suggests the fusion of micropores at elevated temperature. It is considered that the micropores are formed at lower temperature, though their observation was not possible because of the limited resolution in SEM measurement.

\subsection{Elemental Composition}

The results of the elemental analysis are summarized in Table 1. It was revealed that the samples, which were activated with zinc chloride and then washed with hydrochloric acid, had carbon content of around $80 \%$. On the other hand, the carbon composition of the sample without hydrochloric acid treatment was 29 wt\%, which was even lower than that of the unheated holdfast sample. Moreover, the ash content of the unwashed sample was higher than that of the samples washed with hydrochloric acid. Obviously, the activator component remains in the carbonaceous compounds after thermal treatment of the mixture of kelp and $\mathrm{ZnCl}_{2}$, and a chemical removal operation such as hydrochloric acid washing is essential to obtain a material having a high carbon content. As for the ash in the carbonaceous material, the representative results of XRD are shown in Figure 7. Many crystalline peaks were detected for the material without $\mathrm{HCl}$ treatment. The existence of zinc sulfur arouse probably from the reaction between zinc compounds and sulfonate groups in fucoidan. After washing with acid the crystalline materials were largely removed as shown in the figure. Thus, washing treatment is effective for the removal of ash, mainly zinc compounds, although some crystalline phases were still found in the washed sample, indicating the dif- 
ficulties in the removal of zinc compounds which were presumably penetrated deep into the carbonaceous compounds above the melting point of the activator. The complete removal of the ash is one of the future work, though the present study revealed that the preparation of activated carbon is promising with the sufficient carbon content with high specific surface area comparable to a commercial activated carbon.

From the viewpoint of the carbon yield, the activated samples had a higher yield than that of the carbonized samples without activator as shown in Table 1. It is considered that this is because the generation of volatile components, such as tar, was suppressed by the dehydration action of zinc chloride [21] [22] [23]. For further discussion on the influence of the zinc chloride, volatile products evolved during the thermal treatment were studied with GC-MS. As shown in the results in Figure 8, a large number of compounds with 15 to 20 carbon atoms were detected in the volatile fraction from carbonization of holdfast, while GC peaks were hardly detected in the case of activation with zinc chloride. It is considered that the presence of zinc chloride suppressed the generation of volatile organic compounds as described above. Detailed identification of the volatile products was not possible solely from the mass spectrum of each GC peak because of the low confidence coefficient, so that further studies are needed to discuss the detailed reaction mechanisms. On the other hand, as the carbon content is improved by activation with zinc chloride, it is promising to prepare activated carbon with this process.
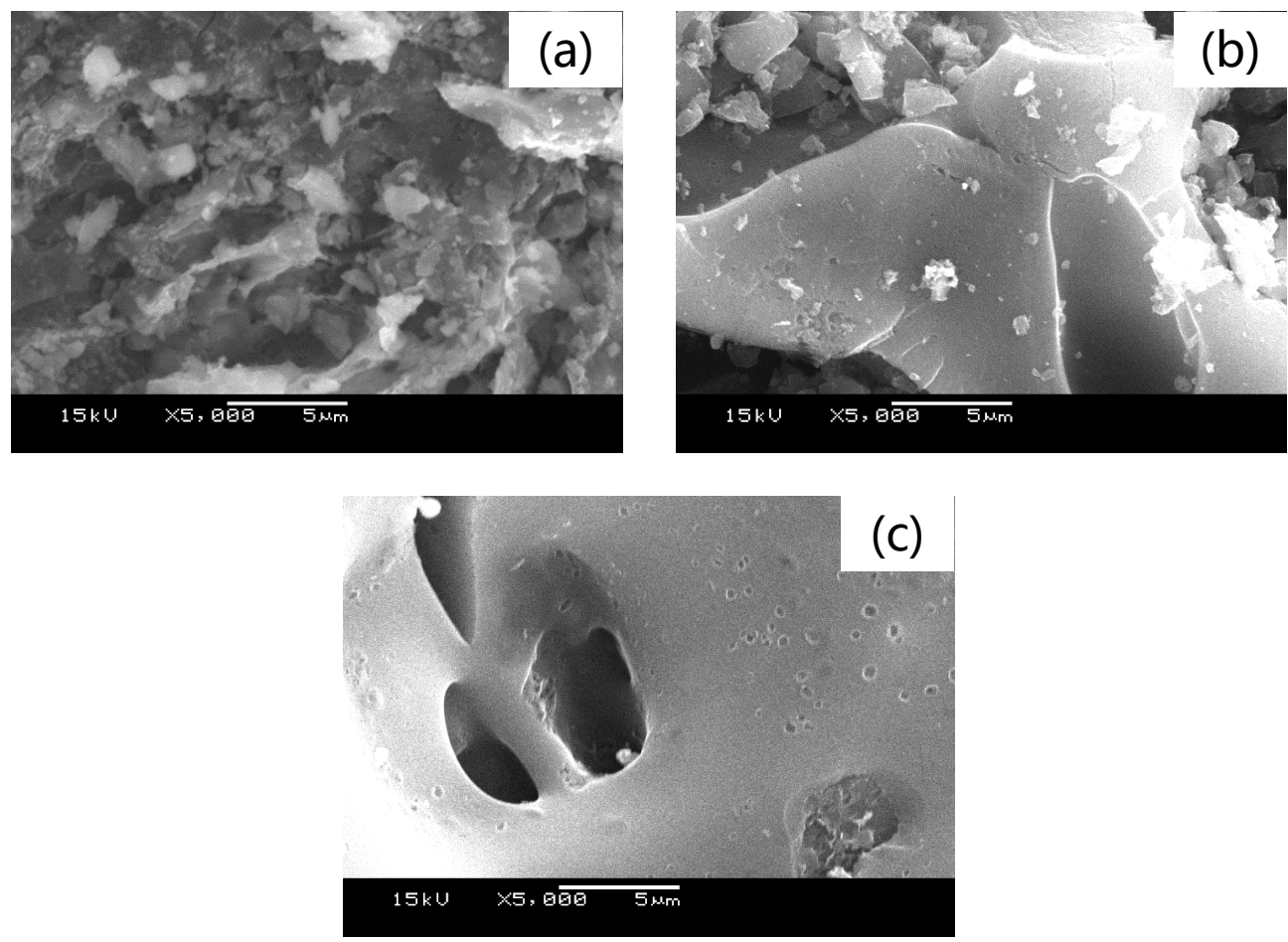

Figure 6. SEM images of carbonized and activated products: (a) carbonized holdfast at $600^{\circ} \mathrm{C}$, (b) and (c) at the composition of $75 \% \mathrm{ZnCl}_{2}$ at $600^{\circ} \mathrm{C}$ and $900^{\circ} \mathrm{C}$, respectively. 


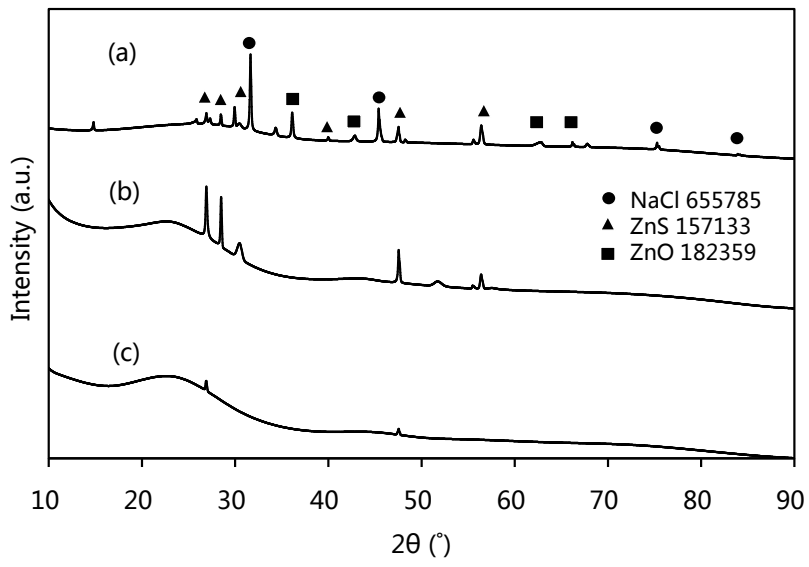

Figure 7. XRD patterns of activated samples obtained at $600^{\circ} \mathrm{C}$ : (a) $75 \% \mathrm{ZnCl}_{2}$ without acid washing, (b) and (c) $50 \%$ and $75 \%$ $\mathrm{ZnCl}_{2}$ with $\mathrm{HCl}$ treatment, respectively. The powder diffraction file numbers of identified substances are listed in the figure.

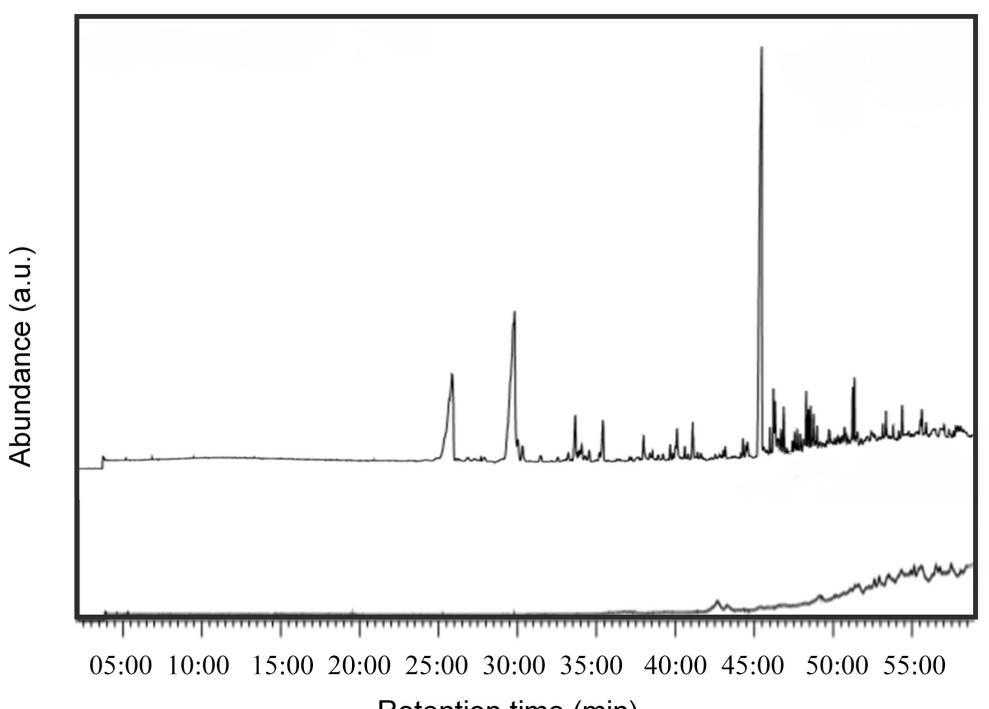

Retention time (min)

Figure 8. GC-MS spectrum of volatile fractions at $900^{\circ} \mathrm{C}$ : (upper panel) carbonization without $\mathrm{ZnCl}_{2}$, (lower panel) with $50 \%$ of $\mathrm{ZnCl}_{2}$.

Table 1. The results of elemental analysis.

\begin{tabular}{cccccc}
\hline & $\begin{array}{c}\mathrm{H} \\
(\mathrm{wt} \%)\end{array}$ & $\begin{array}{c}\mathrm{C} \\
(\mathrm{wt} \%)\end{array}$ & $\begin{array}{c}\mathrm{N} \\
(\mathrm{wt} \%)\end{array}$ & $\begin{array}{c}\text { Ash } \\
(\mathrm{wt} \%)\end{array}$ & Carbon yield (\%) \\
\hline Unheated kelp holdfast & 4.4 & 31 & 1.6 & 5.5 & - \\
$600^{\circ} \mathrm{C}$ (Carbonized) & 1.2 & 41 & 1.3 & 13 & 55 \\
$900^{\circ} \mathrm{C}($ Carbonized) & 1.7 & 66 & 2.5 & 8.6 & 41 \\
$600^{\circ} \mathrm{C}\left(50 \% \mathrm{ZnCl}_{2}\right)$, & 1.8 & 29 & 0.91 & 14 & - \\
$\mathrm{Unwashed}$ & 1.4 & 78 & 3.5 & 1.7 & 68 \\
$600^{\circ} \mathrm{C}\left(50 \% \mathrm{ZnCl}_{2}\right)$ & 1.4 & 78 & 3.7 & 0.11 & 54 \\
$600^{\circ} \mathrm{C}\left(75 \% \mathrm{ZnCl}_{2}\right)$ & 0.66 & 79 & 2.9 & 4.2 & 67 \\
$900^{\circ} \mathrm{C}\left(50 \% \mathrm{ZnCl}_{2}\right)$ & & &
\end{tabular}




\section{Conclusions}

Holdfasts of kelp, Saccharina japonica, were successfully applied for the preparation of activated carbon. The chemical activation using zinc chloride resulted in the increase in the specific surface area, exceeding $1000 \mathrm{~m}^{2} / \mathrm{g}$ at the $\mathrm{ZnCl}_{2}$ composition above 50 mass\%.

Taking into account the fact that the holdfast waste amounts to the thousands of tons only in the southern region of Hokkaido Island in Japan, we consider that the production of activated carbon from holdfast of kelp is promising for the effective usage of its waste. And the findings of the present work will be also useful for the effective utilization of waste of other species of kelp or algae.

As holdfasts contain contaminants, such as nylon ropes and shells adhering on holdfast bodies, so that their influences should be carefully examined in the future work. And the present work obviously triggered further works on the detailed applications of the obtained materials. Examples include adsorbent for wastewater treatment and supercapacitor material.

\section{Acknowledgements}

Financial support by SPG Fukoku Co., Ltd., Kawasaki, Japan is gratefully acknowledged. The authors thank Professor Kensuke Kuroda, Institute of Materials Innovation and staff members of the Chemical Instrumentation Facility, Research Center for Materials Science, Nagoya University for the measurement of the elemental analysis.

\section{Conflicts of Interest}

The authors declare no conflicts of interest regarding the publication of this paper.

\section{References}

[1] Ministry of Agriculture, Forestry and Fisheries, Japan (2020) Statistical Data of Fisheries Production. http://www.maff.go.jp/j/tokei/kouhyou/kaimen_gyosei/

[2] Nagano, A. (2010) Efficient Utilization and Zero Emission of Fisheries Resources III-3 Algae. Nippon Suisan Gakkaishi, 76, 960. (in Japanese) https://doi.org/10.2331/suisan.76.960

[3] Ghimire, K.N., Inoue, K., Ohto, K. and Hayashida T. (2008) Adsorption Study of Metal Ions onto Cross-Linked Seaweed Laminaria japonica. Bioresource Technology, 99, 32-37. https://doi.org/10.1016/j.biortech.2006.11.057

[4] Liu, Y.H., Cao, Q.L., Luo, F. and Chen, J. (2009) Biosorption of $\mathrm{Cd}^{2+}, \mathrm{Cu}^{2+}, \mathrm{Ni}^{2+}$ and $\mathrm{Zn}^{2+}$ Ions from Aqueous Solutions by Pretreated Biomass of Brown Algae. Journal of Hazardous Materials, 163, 931-938. https://doi.org/10.1016/j.jhazmat.2008.07.046

[5] Kuzuhara, S., Kudo, K. and Terakado, O. (2018) Biosorption of Cu(II) Ions by Kelps, Large Brown Algae Seaweeds, Saccharina japonica and Saccharina sculpera. Journal of Sustainable Metallurgy, 4, 455-460. https://doi.org/10.1007/s40831-018-0191-3

[6] Xu, X., Kim, J.Y., Oh, Y.R. and Park, J.M. (2014) Production of Biodiesel from Carbon Sources of Macroalgae, Laminaria japonica. Bioresource Technology, 169, 
455-461. https://doi.org/10.1016/j.biortech.2014.07.015

[7] Smith, A.M. and Ross, A.B. (2016) Production of Bio-Coal, Bio-Methane and Fertilizer from Seaweed via Hydrothermal Carbonization. Algal Research, 16, 1-11. https://doi.org/10.1016/j.algal.2016.02.026

[8] Prakoso, T., Nurastuti, R., Hendriansyah, R., Rizkiana, J., Suantika, G. and Guan, G. (2018) Hydrothermal Carbonization of Seaweed For Advanced Biochar Production. The 24th Regional Symposium on Chemical Engineering, Semarang, 15-16 November 2017, Article ID: 05012. https://doi.org/10.1051/matecconf/201815605012

[9] Lin, Y.W., Zhou, W.P., Di, Y.S., Zhang, X.W., Yang, L. and Gan, Z.X. (2019) Low-Cost Carbonized Kelp for Highly Efficient Solar Steam Generation. AIP Advances, 9, Article ID: 055110. https://doi.org/10.1063/1.5096295

[10] Raymundo-Piñero, E., Cadek, M. and Béguin, F. (2009) Tuning Carbon Materials for Supercapacitors by Direct Pyrolysis of Seaweeds. Advanced Functional Materials, 19, 1032-1039. https://doi.org/10.1002/adfm.200801057

[11] Bichat, M.P., Raymundo-Piñero, E. and Béguin, F. (2010) High Voltage Supercapacitor Built with Seaweed Carbons in Neutral Aqueous Electrolyte. Carbon, 48, 4351-4361. https://doi.org/10.1016/j.carbon.2010.07.049

[12] Pintor, M.J., Jean-Marius, C., Jeanne-Rose, V., Taberna, P.L., Simon, P., Gamby, J., Gadiou, R. and Gaspard, S. (2013) Preparation of Activated Carbon from Turbinaria turbinata Seaweeds and Its Use as Super-Capacitor Electrode Materials. Comptes Rendus Chimie, 16, 73-79. https://doi.org/10.1016/j.crci.2012.12.016

[13] Wang, J., Qin, F., Guo, Z. and Shen, W. (2019) Oxygen- and Nitrogen-Enriched Honeycomb-Like Porous Carbon from Laminaria japonica with Excellent Supercapacitor Performance in Aqueous Solution. ACS Sustainable Chemistry \& Engineering, 7, 11550-11563. https://doi.org/10.1021/acssuschemeng.9b01448

[14] Aravindhan, R., Rao, J.R. and Nair, B.U. (2009) Preparation and Characterization of Activated Carbon from Marine Macro-Algal Biomass. Journal of Hazardous Materials, 162, 688-694. https://doi.org/10.1016/j.jhazmat.2008.05.083

[15] Mohan, D. and Pittman, C.U. (2006) Activated Carbons and Low Cost Adsorbents for Remediation of Tri- and Hexavalent Chromium from Water. Journal of Hazardous Materials, 137, 762-811. https://doi.org/10.1016/j.jhazmat.2006.06.060

[16] Terakado, O. and Hirasawa, M. (2005) Effect of Metal Oxides on the Pyrolysis Residues of Poly(Ethylene Terephthalate): Formation of Carbonaceous Submicron, Nano-Scale Filaments and Mesoporous Compounds. Journal of Analytical and Applied Pyrolysis, 73, 248-256. https://doi.org/10.1016/j.jaap.2005.02.002

[17] Terakado, O., Ueda, M. and Hirasawa, M. (2010) Thermal Degradation of Polyester-Metal Oxide Mixtures: Fibrous Morphology of Carbonaceous Compounds and Pyrolysis Products Distribution. Journal of Analytical and Applied Pyrolysis, 89, 183-190. https://doi.org/10.1016/j.jaap.2010.08.001

[18] Burrage, L.J. (1933) Studies on Adsorption. Part I. Mechanism of the Activation of Charcoal. Transactions of the Faraday Society, 29, 445-457.

https://doi.org/10.1039/TF9332900445

[19] Schmidt, S.A., Kumar, N., Shchukarev, A., Eränen, K., Mikkola, J.P., Murzin, D. and Salmi, T. (2013) Preparation and Characterization of Neat and $\mathrm{ZnCl}_{2}$ Modified Zeolites and Alumina for Methyl Chloride Synthesis. Applied Catalysis A: General, 468, 120-134. https://doi.org/10.1016/j.apcata.2013.08.039

[20] Oishi, S., Amano, Y., Aikawa, M. and Machida, M. (2011) Adsorption of Pb(II) Ion on Mesoporous Activated Carbon Prepared by $\mathrm{ZnCl}_{2}$ Activation. TANSO, 250, 231-237. (In Japanese) https://doi.org/10.7209/tanso.2011.231 
[21] Smith, K.M., Fowler, G.D., Pullket, S. and Graham, N.J.D. (2009) Sewage Sludge-Based Adsorbents: A Review of Their Production, Properties and Use in Water Treatment Applications. Water Research, 43, 2569-2594. https://doi.org/10.1016/j.watres.2009.02.038

[22] Duman, G., Onal, Y., Onenc, S. and Yanik, J. (2009) Production of Activated Carbon from Pine Cone and Evaluation of Its Physical, Chemical, and Adsorption Properties. Energy \& Fuels, 23, 2197-2204. https://doi.org/10.1021/ef800510m

[23] Bagreev, A., Locke, D.C. and Bandosz, T.J. (2001) $\mathrm{H}_{2} \mathrm{~S}$ Adsorption/Oxidation on Adsorbents Obtained from Pyrolysis of Sewage-Sludge-Derived Fertilizer Using Zinc Chloride Activation. Industrial \& Engineering Chemistry Research, 40, 3502-3510. https://doi.org/10.1021/ie010165w 